Article

\title{
Oxidation Simulation of Thermal Barrier Coatings with Actual Microstructures Considering Strength Difference Property and Creep-Plastic Behavior
}

\author{
Chen $\operatorname{Lin}^{1,2}$, Yijun Chai ${ }^{2,3}$ and Yueming $\mathrm{Li}^{2,3, *}$ \\ 1 School of Mechanical Engineering, Xi'an Jiaotong University, Xi'an 710049, China; \\ linchen19870117@stu.xjtu.edu.cn \\ 2 State Key Laboratory for Strength and Vibration of Mechanical Structures, Xi'an Jiaotong University, \\ Xi'an 710049, China; cyj1991@stu.xjtu.edu.cn \\ 3 Shaanxi Key Laboratory of Environment and Control for Flight Vehicle, School of Aerospace Engineering, \\ $\mathrm{Xi}^{\prime}$ an Jiaotong University, Xi'an 710049, China \\ * Correspondence: liyueming@mail.xjtu.edu.cn; Tel.: +86-29-8266-8340
}

Received: 28 July 2018; Accepted: 12 September 2018; Published: 25 September 2018

\begin{abstract}
A scanning electron microscope (SEM) image based direct finite element (FE) mesh reconstruction method is employed to reflect microstructure features of thermal barrier coatings (TBC). The creep-plastic assumption of thermally grown oxide (TGO) scale and metallic bond coat (BC) as well as the strength difference (SD) property of ceramic top coat (TC) are considered to simulate the mechanical behavior. A diffusion oxidation model considering oxygen consumption is proposed to characterize TGO growth. The oxidation simulation of TBC is carried out under the consideration of actual microstructure features. The results revealed that the interface defects increase the surface-area-to-volume ratio of BC exposed to oxygen anion. This leads to the non-uniform TGO growth, which has also been observed in experimental studies. The microstructures and mechanical behavior strongly affect stress evolution in TBC. The consideration of actual microstructure features and reasonable mechanical behaviors, including the creep-plastic behavior and SD property, is helpful for the accurate evaluation of interface stress.
\end{abstract}

Keywords: thermal barrier coatings; actual microstructures; creep-plastic assumption; strength difference property; oxidation simulation

\section{Introduction}

The thermal barrier coatings (TBC), consisting of the high temperature resistant ceramic top coat (TC), oxygen anion permeation resistant thermally grown oxide (TGO) scale, and metallic bond coat (BC) enable gas turbine to withstand super-high gas temperature and extreme oxidation-corrosion [1]. It is one of the indispensable elements for hot-end components. The application of TBC, however, is seriously restricted by premature failure during service. The stress, especially along interfaces, is considered to be primarily responsible for TBC failure [2]. The interface stress induces damage initiation and progression in the form of microcracks and finally leads to ultimate spallation of TBC, which is mainly influenced by the factors as follows:

- The microstructures of TBC, including complex interface morphology and randomly distributed microdefects;

- The mechanical behavior, for instance, the creep and plastic deformation often occurs during service; 
- TGO growth, resulting from the oxidation of BC, which causes permanent volumetric swelling and mechanical property mismatch, such as the significant thermal expansion differences among TC, TGO and BC.

The microstructure in TBC plays an important role in gas turbine and is, meanwhile, not well understood yet. Thus, the first challenge is how to represent such microstructures accurately in FE mesh. The simplest FE mesh is the unit cell, in which the interfaces are idealized to be wavy or sinusoidal with microdefects free. Based on this, it might be easy to analyze the effect of interface roughness on stress developments. However, the influences of actual microstructures on oxidation failure of TBC cannot be reflected via this approach. With the advances of digital image processing technology (e.g., SEM tool), the new geometrical modeling approaches have been developed to characterize TBC microstructures in detail [3-6]. Based on the method, the inherent interface morphology, microdefects distribution, and material composition are incorporated into the geometrical model. Such a geometrical model, however, needs to be additionally meshed before FE analyses. Besides, the prediction precision tends to decrease as the elements, near complex geometrical surface, are likely meshed in triangular or tetrahedral form. Recently, some researchers propose the SEM image based direct FE mesh reconstruction method, which is recognized effectively to study micro-crack growth for TBC [7]. In the present paper, a SEM image based direct FE mesh reconstruction method, reported by us [8], is utilized to represent the microstructure features of TBC. Based on the method, the microstructure features of TBC can be distinguished and characterized by the gray-scale of SEM image and then directly mapped to FE mesh with uniform rectangular or hexahedral elements.

The accurate prediction of stress in TBC also relies on the reasonable characterizations of mechanical behaviors. TC, a kind of ceramic material, has been confirmed that there exists a significant difference between compressive and tensile yield strengths. This is called the strength differences (SD) property. The experimental research $[9,10]$ shows that the compressive strength of ceramic coating is 10 times greater than its tensile strength. The SD property of ceramic coating significantly affect the stress evolution in TBC. However, this has not been adequately considered. To reflect SD property of TC, unified strength theory (UST), proposed by Yu [11], is employed, which could comprehensively consider strength difference. A return mapping algorithm model, proposed by Chen et al. [12,13], then is used for simulation. TGO and BC are usually simulated as elastic-to-plastic materials [14]. As the stress is found to be significantly relaxed by creep at high temperature, creep rather than plastic constitutive theory is mainly applied to the stress prediction in the current numerical studies [15-17]. The visco-plastic constitutive model proposed by Chaboche et al. [18] is also employed to reflect the rate dependent deformation behavior of TBC. In this model, the creep and plastic strains are assumed to be indistinguishable, which are represented in a unified way by one parameter called the visco-plastic strain. The creep and plastic behaviors are, in fact, governed by different mechanisms [19]. The plasticity is non-reversible deformation with no time-dependence in response to applied forces, while creep is time-dependent deformation which might occur under the very low level of stress within the yield limit. Thus, a creep-plastic constitutive relationship, proposed by Chen et al. [20], is employed to characterize the deformation behaviors of TGO and BC.

TGO growth is also a research focus. Many theoretical, experimental, and numerical approaches have been implemented to study TGO growth and probe the oxidation mechanism. The existing phenomenological model describes a parabolic relation between time and thickness of oxide layer. It's the most simple and common model and widely applied in simulation [15-18]. The parameters of the model, however, need to be determined through a long-term experiment (usually several hundred hours). Furthermore, this kind of phenomenological model cannot capture the oxidation mechanism. The numerical model based on the classical Fick's first law [21,22] could better predict the oxide growth. In this model, the evolution of oxide scale is dependent on the concentration of reactants. The consumption of reactants in oxidation, however, is ignored. Taking the consumption of reactants into account, Chen et al. $[13,20]$ proposed a diffusion-oxidation model, in which the Fick's law is modified by adding a reaction term. 
As above mentioned, the microstructure, mechanical behavior and TGO growth could significantly affect the stress evolution. The accurate representation of microstructures and appropriate characterization of mechanical behavior and TGO growth would be helpful to investigate the failure mechanisms of TBC. To this end, an analytical/numerical strategy with three innovative considerations is proposed in present study. Firstly, an SEM image-based method is utilized to build the FE mesh of $\mathrm{TBC}$, in which the actual microstructures are taken into account. Secondly, the SD property of TC and the combined creep and plastic behavior of TGO and BC are considered to simulate the mechanical behavior. Thirdly, the diffusion-oxidation model is applied to explore TGO growth. Based on the proposed approach, an oxidation simulation of TBC is carried out to investigate TGO growth and stress development. One idealized TBC model with cosine shaped interface is also adopted for comparison.

\section{Methodology}

\subsection{SEM Image Based Direct FE Mesh Reconstruction}

Considering a typical TBC system with random distributed microstructures, as shown in Figure 1a, where the difference in the densities of phases leads to the different grayscale values of pixels. With the present reconstruction method, the grayscale values of pixels could be collected. The corresponding grayscale histogram and cumulative distribution for SEM images are plotted in Figure $2 b$. Then, the grayscale values of pixels are distinguished by the given thresholds to represent different phases. In present paper, two thresholds $(T 1=96$ and $T 2=168$, as shown in Figure $2 \mathrm{~b}$ ) are adopted to distinguish three phases. The pixels in the image with lower grayscales than thresholds, $T 1$, belongs to the TC phase. While the pixels with grayscales in the interval (T1 and T2) belongs to the BC phase. The remaining phase, i.e., grayscales is higher than $T 2$, represents the micro defect. Finally, the different phase would correspond to different materials and the corresponding position coordinates of pixels would be mapped as node coordinates in FE mesh.

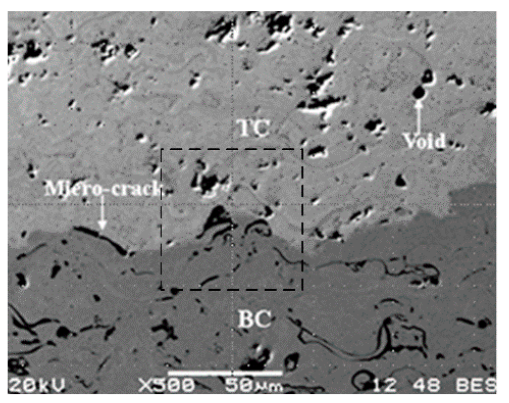

(a)

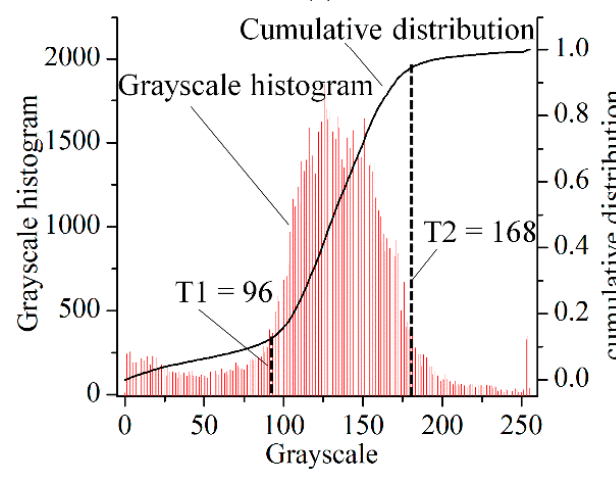

(b)

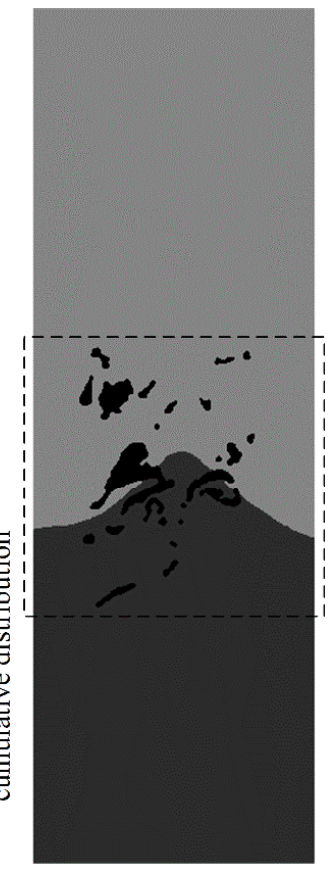

(c)

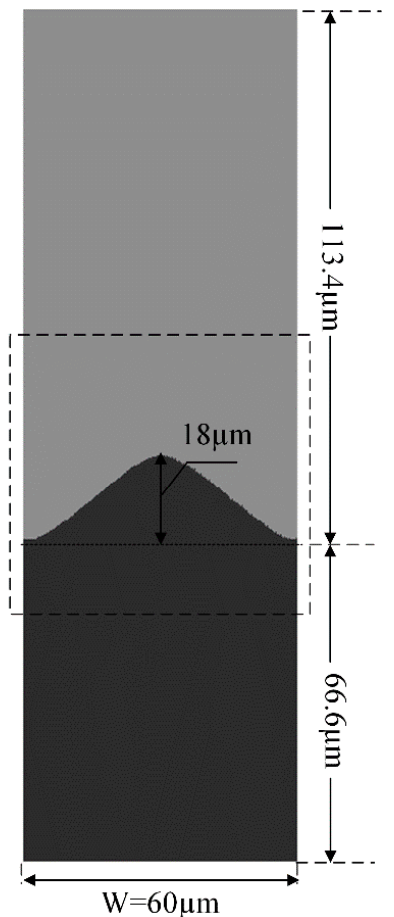

(d)

Figure 1. (a) SEM image of cross-sectional microstructures of TBC [7], (b) grayscale histogram and cumulative distribution for SEM images, (c) SEM image based FE mesh, and (d) FE mesh with idealized interface. 


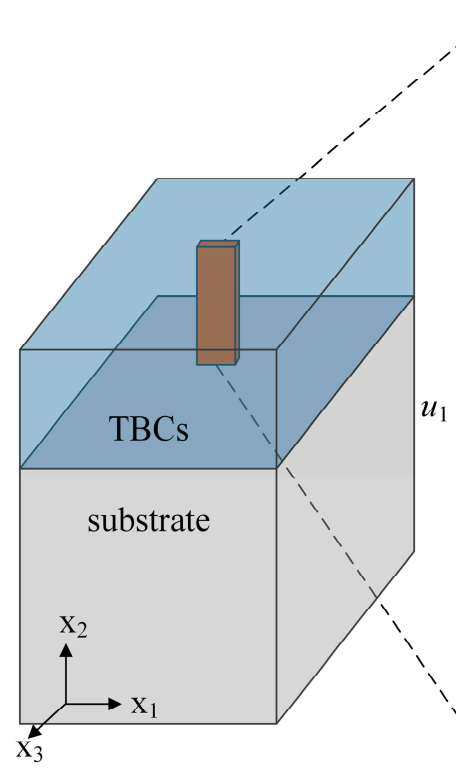

(a)

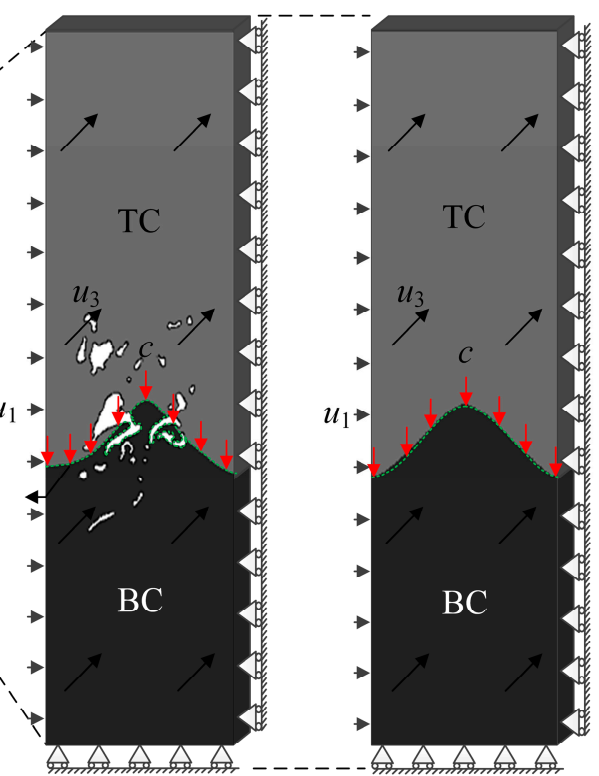

(b)

(c)

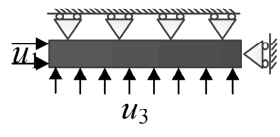

(d)

Figure 2. (a) Schematization of TBC; Boundary conditions for the simulated domain of TBC with (b) cosine-interface and (c) actual microstructures; and (d) Top view image of the simulated domain.

In this paper, one small portion of SEM image is extracted for the FE mesh reconstruction. The layers of material are extended to representative dimensions, i.e., TC and BC, respectively, heights to be $113.4 \mu \mathrm{m}$ and $66.6 \mu \mathrm{m}$. The final mesh with two dimensional, four-node rectangular elements, based on SEM images, is illustrated in Figure 1c. One more mesh with idealized interface, established for comparison, is shown in Figure 1d. Considering that the accuracy of analyzing stress development is related to the mesh density, the element size is chosen to be $0.25 \mu \mathrm{m}$, and in total, 172,800 elements are counted in both meshes.

\subsection{Mechanical Behavior Modeling}

In this paper, unified strength theory (UST) [11] is employed for the description of plastic behavior of TC. The mathematical formulation of UST, in the sextant of principal stress space $\sigma_{1} \geq \sigma_{2} \geq \sigma_{3}$, is given as follows,

$$
\begin{gathered}
F \equiv \sigma_{1}-\frac{\alpha}{1+b}\left(b \sigma_{2}+\sigma_{3}\right)=\sigma_{\mathrm{t}}, \text { when } \sigma_{2} \leq \frac{\sigma_{1}+\alpha \sigma_{3}}{1+\alpha} \\
F^{\prime} \equiv \frac{1}{1+b}\left(\sigma_{1}+b \sigma_{2}\right)-\alpha \sigma_{3}=\sigma_{\mathrm{t}}, \text { when } \sigma_{2} \geq \frac{\sigma_{1}+\alpha \sigma_{3}}{1+\alpha}
\end{gathered}
$$

where $\sigma_{t}$ is tensile yield strength, $\alpha$ is tensile-compressive strength ratio to reflect SD property, and $b$ is a parameter that describes the effect of intermediate principal stress on the failure of material. The return mapping algorithm model is proposed by Chen et al. [12] for simulation. The details of the algorithm model is in Reference [12]. Here, only the brief processes of stress-update are introduced in Appendix A.

The deformation behaviors of TGO and BC are characterized by the creep-plastic constitutive model, introduced by us [18] (the algorithm of stress-update are in Appendix B) as follows,

$$
\begin{gathered}
\varepsilon_{\mathrm{TGO}}=\varepsilon_{\mathrm{TGO}}^{\mathrm{th}}+\varepsilon_{\mathrm{TGO}}^{\mathrm{e}}+\varepsilon_{\mathrm{TGO}}^{\mathrm{p}}+\varepsilon_{\mathrm{TGO}}^{\mathrm{c}}+\varepsilon_{\mathrm{TGO}}^{\mathrm{g}} \\
\varepsilon_{\mathrm{BC}}=\varepsilon_{\mathrm{BC}}^{\mathrm{th}}+\varepsilon_{\mathrm{BC}}^{\mathrm{e}}+\varepsilon_{\mathrm{BC}}^{\mathrm{p}}+\varepsilon_{\mathrm{BC}}^{\mathrm{c}}
\end{gathered}
$$

where the subscripts TGO and BC, respectively, represent the TGO and BC materials; $\varepsilon^{\text {th }}$ is thermal strain; $\varepsilon^{\mathrm{g}}$ represents permanent volumetric swelling strain; $\varepsilon^{\mathrm{p}}$ is plastic strain; and $\varepsilon^{\mathrm{c}}$ is creep strain. 
In Equations (3) and (4), the thermal strain and the volumetric swelling strain are directly given as follows:

$$
\begin{gathered}
\varepsilon_{\mathrm{TGO}(\text { or BC) }}^{\text {th }}=\alpha_{\mathrm{TGO}(\text { or BC) }}\left(T-T_{\text {ref }}\right) I \\
\varepsilon_{\mathrm{TGO}}^{\mathrm{g}}=\varepsilon_{\mathrm{V}}^{\mathrm{g}} I
\end{gathered}
$$

where $\alpha_{\mathrm{TGO}}$ (or BC) is the thermal expansion coefficients of TGO or BC, $\varepsilon_{\mathrm{V}}^{\mathrm{g}}=0.08$ is the is the mean volumetric swelling strain which is determined by Pilling-Bed worth ratio [15], $T_{\text {ref }}$ is the reference temperature, and I is the second-order identity tensor.

The increment of plastic strain $d \varepsilon^{\mathrm{p}}$ is derived from the plastic flow rule based on von-Mises yield criterion, as follows:

$$
d \varepsilon^{\mathrm{p}}=d \varepsilon_{\mathrm{eq}}^{\mathrm{p}} \frac{\partial q(\sigma)}{\partial \sigma}
$$

where $d \varepsilon_{\mathrm{eq}}^{\mathrm{p}}$ is the increment of equivalent plastic strain and $q(\sigma)$ is the von-Mises equivalent stress.

The Norton-type creep is adopted for the derivation of increment of creep strain $d \varepsilon^{c}$ in the form:

$$
\begin{gathered}
d \varepsilon^{\mathrm{c}}=d \varepsilon_{\mathrm{eq}}^{\mathrm{c}} \frac{\partial q(\sigma)}{\partial \sigma} \\
d \varepsilon_{\mathrm{eq}}^{\mathrm{c}}=A[q(\sigma)]^{\rho} \exp \left(\frac{-Q}{R T}\right) d t
\end{gathered}
$$

where $d \varepsilon_{\mathrm{eq}}^{c}$ is an increment of equivalent creep strains; $A, \rho, Q, R, T$, are, respectively, the reference creep strain rate, creep exponent, creep activation energy, ideal gas constant, and thermodynamic temperature.

\subsection{Diffusion Oxidation Scheme for TGO Growth}

In this paper, a diffusion oxidation scheme, proposed by Chen et al. [13,20], is adopted to simulate TGO growth. In the diffusion oxidation scheme, TGO-BC interface is assumed to be a gradually moving oxidation front, in which TGO and BC phases coexist,

$$
f_{\mathrm{BC}}+f_{\mathrm{TGO}}=1
$$

where $f$ represents dimensionless molar fraction. In the oxidation front, Voigt's homogenization assumption is utilized to characterize the mechanics behavior, as follows:

$$
\begin{gathered}
\varepsilon=\varepsilon_{\mathrm{BC}}=\varepsilon_{\mathrm{TGO}} \\
\sigma=(1-\xi) \sigma_{\mathrm{BC}}+\xi \sigma_{\mathrm{TGO}}
\end{gathered}
$$

where $\xi=f_{\mathrm{TGO}}$ is the dimensionless molar fraction of TGO. Substituting Equations (3), (4) and (11) into Equation (12), the constitutive relationship in oxidation front is derived:

$$
\begin{aligned}
\sigma= & (1-\xi) D_{\mathrm{BC}}^{\mathrm{e}}:\left(\varepsilon-\varepsilon_{\mathrm{BC}}^{\text {th }}-\varepsilon_{\mathrm{BC}}^{\mathrm{p}}-\varepsilon_{\mathrm{BC}}^{\mathrm{c}}\right)+ \\
& \xi D_{\mathrm{TGO}}^{\mathrm{e}}:\left(\varepsilon-\varepsilon_{\mathrm{TGO}}^{\text {th }}-\varepsilon_{\mathrm{TGO}}^{\mathrm{p}}-\varepsilon_{\mathrm{TGO}}^{\mathrm{c}}-\varepsilon_{\mathrm{TGO}}^{\mathrm{g}}\right)
\end{aligned}
$$

In the simulation, $\xi$ varies from 0 to 1 to describe oxidation process. The rate of $\xi$ represents oxidation rate. With the reference of alkali-silica reaction model proposed by Reference [23], the rate of $\xi$ can be assumed to be controlled by the concentration of mobile oxygen anions $\mathrm{c}$ and the available $\mathrm{BC}$ material $1-\xi$, in the form of:

$$
\frac{d \xi}{d t}=\gamma c(1-\xi)
$$

where $\gamma$ is a constant which needs to be calibrated from oxidation data. 
To determine the distribution of concentration of oxygen anions, a modified Fick's law is introduced in the form of:

$$
\frac{d c}{d t}=D \operatorname{div}(\nabla c)+S(c)
$$

where div and $\nabla$ are, respectively, the divergence operator and gradient operator; $D$ is oxygen diffusion coefficient, in the form of $D=(1-\xi) D_{\mathrm{BC}}+\xi D_{\mathrm{TGO}}$. The oxygen anion diffusion coefficient is considered to be temperature-dependent:

$$
D=D_{0} \exp \left(-\frac{Q_{\mathrm{d}}}{R T}\right)
$$

where $D_{0}$ and $Q_{\mathrm{d}}$ are, respectively, reference oxygen anion diffusion coefficient and oxygen anion diffusion activation energy.

$S(c)$ represents moles of oxygen anion consumed per unit time and volume during oxidation, expressed as follows:

$$
S(c)=-\kappa \frac{d \xi}{d t}
$$

where $\mathrm{k}$ is the moles of oxygen anion consumed to generate unit molar volume TGO.

\subsection{Boundary Condition for Oxidation of TBC}

Based on the proposed numerical approach, the oxidation simulation is carried out. In the simulation, a thin section of TBC is employed, as shown in Figure 2. The microstructure features in the $x_{3}$ direction is assumed to be changeless.

TBC is exposed in $1373 \mathrm{~K}$ for $300 \mathrm{~h}$, and then cooled down to $293 \mathrm{~K}$ within $120 \mathrm{~s}$. Since the heat conduction is not considered, all node of the FE mesh is assumed to undergo the same temperature history. At the beginning, TBC is regarded as stress-free. The upper surface is assumed to be unconstrained, while the other surfaces are constrained by the frictionless movable hinge support. On cooling, to investigate the influence of thermal contraction imposed by the substrate on TBC, the left surface is allowed to move in the $\mathrm{x}_{1}$ direction with the same displacement $u_{1}$ (as shown in Figure $2 b, c)$, as follows:

$$
u_{1}=\alpha_{\text {sub }}\left(T-T_{\text {ref }}\right) \mathrm{W}
$$

where $\alpha_{\text {sub }}$ is thermal expansion coefficient of substrate, and $W$ is width of TBC. Meanwhile, a uniform rigid displacement $u_{3}$ is applied to TBC (see Figure $2 \mathrm{~d}$ ) in the form of $u_{3}=\alpha_{\text {sub }}\left(T-T_{\text {ref }}\right) D$, where $D$ is the thickness of TBC.

Since the displacement $u_{3}$ is uniform, the above-mentioned three-dimensional FE analyses could be reduced to a two dimensional generalized plane strain FE analysis [24], as shown in Figure 3. The displacement $u_{3}$ now is reduced to the equal strain applied to all nodes of the two dimensional FE mesh in the direction normal to the $\mathrm{x}_{1}-\mathrm{x}_{2}$ plane (see Figure $3 \mathrm{c}$ ), as follows:

$$
\varepsilon_{33}=\alpha_{\text {sub }}\left(T-T_{\text {ref }}\right)
$$

Concerning the extremely short cooling time, the diffusion oxidation only takes place at the high temperature stage. Since the TC layer is commonly regarded to be fully transparent to oxygen and the oxidation reaction does not occur on the TC layer, the TC top surface is assumed to be equal to the $\mathrm{TC}-\mathrm{BC}$ interface in the concentration of oxygen anions. 


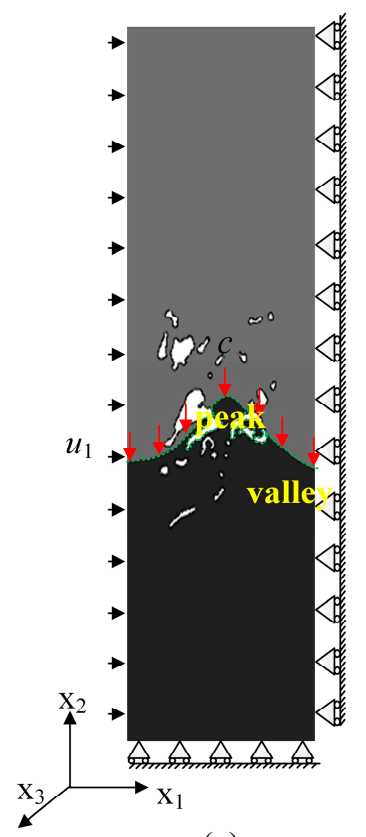

(a)

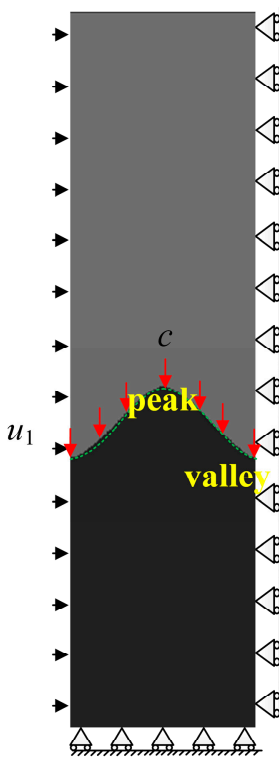

(b)

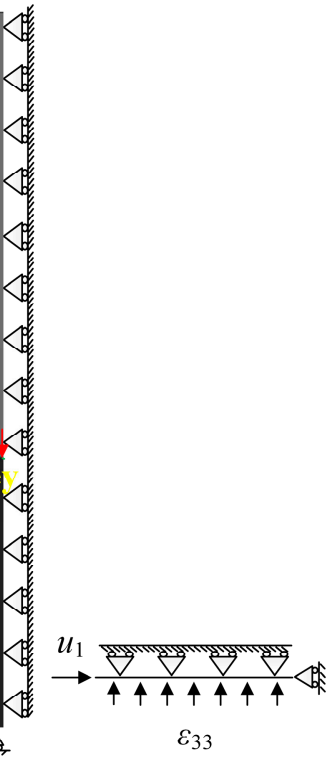

(c)

Figure 3. Boundary conditions for the two dimensional FE mesh with (a) cosine-interface and (b) actual microstructure features; and (c) Top view image of FE mesh.

At the TC-BC interface, the equilibrium condition between the chemical potential of oxygen molecule in the gas and chemical potential of oxygen anion in solid should be satisfied. The ideal chemical potential for oxygen molecule is given as follows,

$$
\mu_{\mathrm{O}_{2}}=\mu_{\mathrm{O}_{2}}^{0}+R T \ln \left(p / p^{0}\right)
$$

where $\mu_{\mathrm{O}_{2}}$ is the chemical potential of oxygen molecule, $\mu_{\mathrm{O}_{2}}^{0}$ is the chemical potential in the standard state, $p$ is the partial pressure of oxygen molecule in gas, and $p^{0}$ is the standard atmospheric pressure.

The corresponding chemical potential of oxygen anion is in the form of:

$$
\mu_{\mathrm{O}}=\mu^{0}+R T \ln \left(c / c_{\max }\right)
$$

where $\mu_{O}$ is the chemical potential of oxygen anion, $\mu^{0}$ is the chemical potential in the standard state, and $c_{\max }$ is the maximum mole concentration of oxygen anion per unit volume.

Following Anand et al. [25], the equilibrium condition between the chemical potentials of oxygen molecule in gas and oxygen anion in solid can be established based on the formulation $1 / 2 \mathrm{O}_{2} \leftrightarrow \mathrm{O}$, as follows:

$$
\frac{1}{2} \mu_{\mathrm{O}_{2}}=\mu_{\mathrm{O}}
$$

\section{Results}

The mechanical properties used in the simulation are taken from the literature and reports and are listed in Tables 1-3. The substrate is treated as PWA 1480. Its thermal expansion properties are taken from Reference [26]. TC is treated as the APS ceramic and are assumed to be the perfect elastic-to-plastic material with an SD property. Its thermal elastic properties are taken from Reference [26] and plastic properties are taken from Reference [9]. BC, consisting of MCrAlY alloy, is assumed to be the creep-plastic material. Its thermal elastic and plastic properties are taken from Reference [26] and the creep properties are taken form Reference [27]. TGO, consisting of $\alpha-\mathrm{Al}_{2} \mathrm{O}_{3}$, is treated as the creep-plastic material too. The corresponding elastic and creep properties are taken form 
References [26] and [15], and the plastic properties are from Reference [14]. The diffusion and oxidation parameters are listed in Table 4.

Table 1. Temperature dependent parameters of TC and substrate.

\begin{tabular}{|c|c|c|c|c|c|c|}
\hline \multirow{2}{*}{$T(\mathrm{~K})$} & \multicolumn{5}{|c|}{ TC } & \multirow{2}{*}{$\begin{array}{c}\text { Substrate } \\
\alpha\left(10^{-6} /{ }^{\circ} \mathrm{C}\right)[26]\end{array}$} \\
\hline & $E$ (GPa) [26] & $v[26]$ & $\alpha\left(10^{-6} /{ }^{\circ} \mathrm{C}\right)[26]$ & $\sigma_{t}(\mathrm{GPa})[9]$ & $\sigma_{c}(G P a)[9]$ & \\
\hline 293 & 48 & 0.1 & 9.7 & 0.40 & 0.172 & 14.8 \\
\hline 473 & 47 & 0.1 & 9.8 & - & - & 15.2 \\
\hline 673 & 44 & 0.1 & 9.9 & - & - & 15.6 \\
\hline 873 & 40 & 0.11 & 9.9 & - & - & 16.2 \\
\hline 1073 & 34 & 0.11 & 10 & - & - & 16.9 \\
\hline 1273 & 26 & 0.12 & 10.1 & - & - & 17.2 \\
\hline 1373 & 22 & 0.12 & 10.1 & - & - & 17.6 \\
\hline
\end{tabular}

Table 2. Material properties of BC.

\begin{tabular}{|c|c|c|c|c|c|c|c|}
\hline \multirow[b]{2}{*}{$T(\mathrm{~K})$} & \multicolumn{7}{|c|}{ BC } \\
\hline & $\begin{array}{c}E_{\mathrm{BC}} \\
(\mathrm{GPa})[26]\end{array}$ & $\begin{array}{l}v_{\mathrm{BC}} \\
{[26]}\end{array}$ & $\begin{array}{c}\alpha_{\mathrm{BC}} \\
\left(10^{\left.-6 /{ }^{\circ} \mathrm{C}\right)[26]}\right.\end{array}$ & $\begin{array}{c}\sigma_{\mathrm{y}, \text { BC }} \\
(\mathrm{MPa})[26]\end{array}$ & $\begin{array}{c}A_{\mathrm{BC}} \\
\left(\mathrm{MPa}^{-2.2} \mathrm{~s}^{-1}\right)[27]\end{array}$ & $\begin{array}{l}\rho_{\mathrm{BC}} \\
{[27]}\end{array}$ & $\underset{(\mathrm{J} / \mathrm{mol})[27]}{Q_{\mathrm{BC}}}$ \\
\hline 293 & 200 & 0.3 & 12.3 & 426 & $6.31 \times 10^{-6}$ & 2.2 & 165,000 \\
\hline 473 & 190 & 0.3 & 13.2 & 412 & - & - & - \\
\hline 673 & 175 & 0.31 & 14.2 & 396 & - & - & - \\
\hline 873 & 160 & 0.31 & 15.2 & 362 & - & - & - \\
\hline 1073 & 145 & 0.32 & 16.3 & 284 & - & - & - \\
\hline 1273 & 120 & 0.33 & 17.2 & 202 & - & - & - \\
\hline 1373 & 110 & 0.33 & 17.7 & 114 & - & - & - \\
\hline
\end{tabular}

Table 3. Material properties of TGO.

\begin{tabular}{|c|c|c|c|c|c|c|c|}
\hline \multirow[b]{2}{*}{$T(\mathrm{~K})$} & \multicolumn{7}{|c|}{ TGO } \\
\hline & $\begin{array}{c}E_{\mathrm{TGO}} \\
(\mathrm{GPa})[26]\end{array}$ & $\begin{array}{l}v_{\text {TGO }} \\
{[26]}\end{array}$ & $\begin{array}{c}\alpha_{\mathrm{TGO}} \\
\left(10^{\left.-6 /{ }^{\circ} \mathrm{C}\right)}[26]\right.\end{array}$ & $\begin{array}{l}\sigma_{\text {y, TGO }} \\
(\mathrm{GPa})[14]\end{array}$ & $c \frac{A_{\mathrm{TGO}}}{\left(\mathrm{MPa}^{-2.3} \mathbf{s}^{-1}\right)}$ & $\begin{array}{l}\rho_{\mathrm{TGO}} \\
{[15]}\end{array}$ & $\begin{array}{c}Q_{\text {TGO }} \\
(\mathrm{J} / \mathrm{mol})[15]\end{array}$ \\
\hline 293 & 400 & 0.23 & 8 & 10 & $6.8 \times 10^{3}$ & 2.3 & 424,000 \\
\hline 473 & 390 & 0.23 & 8.2 & 10 & - & - & - \\
\hline 673 & 380 & 0.24 & 8.4 & 10 & - & - & - \\
\hline 873 & 370 & 0.24 & 8.7 & 10 & - & - & - \\
\hline 1073 & 355 & 0.25 & 9 & 10 & - & - & - \\
\hline 1273 & 325 & 0.25 & 9.3 & 1 & - & - & - \\
\hline 1373 & 320 & 0.25 & 9.5 & 1 & - & - & - \\
\hline
\end{tabular}

Table 4. Diffusion and oxidation parameters.

\begin{tabular}{lcc}
\hline \multicolumn{1}{c}{ Diffusion and oxidation parameters } & Symbols & Values \\
\hline Reference diffusion coefficients of oxygen in BC [25] & $D_{0, \mathrm{BC}}\left(\mathrm{m}^{2} / \mathrm{s}\right)$ & $7.5 \times 10^{-9}$ \\
Reference diffusion coefficients of oxygen in TGO [25] & $D_{0, \mathrm{TGO}\left(\mathrm{m}^{2} / \mathrm{s}\right)}$ & $7.5 \times 10^{-9}$ \\
Oxygen anion diffusion activation energies of BC [25] & $Q_{\mathrm{d}, \mathrm{TGO}(\mathrm{kJ} / \mathrm{mol})}$ & 100 \\
Oxygen anion diffusion activation energies of TGO [25] & $Q_{\mathrm{d}, \mathrm{TGO}(\mathrm{kJ} / \mathrm{mol})}$ & 100 \\
Ideal gas constant & $R(\mathrm{~kJ} /(\mathrm{mol} \times \mathrm{K}))$ & $8.13 \times 10^{-3}$ \\
Chemical potential of oxygen molecule in the Standard state [25] & $\mu_{\mathrm{O} 2}^{0}(\mathrm{~kJ} / \mathrm{mol})$ & 0 \\
Chemical potential of oxygen anion in the Standard state [25] & $\mu_{0}(\mathrm{~kJ} / \mathrm{mol})$ & 112 \\
Standard atmospheric pressure & $p_{0}(\mathrm{MPa})$ & 0.1 \\
Partial pressure of oxygen molecule in gas [25] & $P(\mathrm{MPa})$ & 0.021 \\
Maximum mole concentration of oxygen anion Per unit volume [25] & $c_{\mathrm{max}}\left(\mathrm{mol} / \mathrm{m}^{3}\right)$ & $0.08 \times 10^{6}$ \\
Moles of oxygen anion consumed to generate Unit volume TGO [25] & $\mathrm{K}\left(\mathrm{mol} / \mathrm{m}^{3}\right)$ & $0.24 \times 10^{6}$ \\
Reference thermodynamic temperature & $T_{\mathrm{ref}}(\mathrm{K})$ & 1373 \\
\hline
\end{tabular}

The parameter $\gamma$, appearing in Equation (9), is calibrated by the experiment data [28] of TGO thickness. When the parameter $\gamma$ is chosen to be $1.25 \times 10^{-4} \mathrm{~m}^{3} /(\mathrm{mol} \times \mathrm{s})$, the predicted TGO 
thickness agrees well with the experiment data, as shown in Figure 4. It means that the proposed diffusion oxidation model is suitable to the oxidation simulation of TBC.

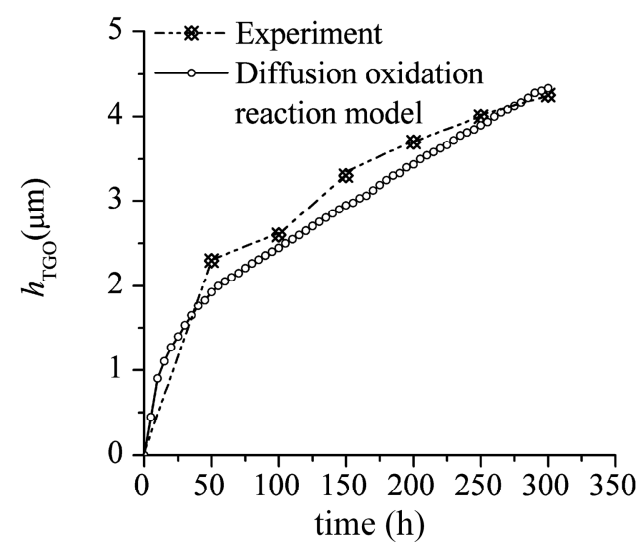

Figure 4. Evolution of TGO thickness using the proposed diffusion oxidation model.

\subsection{TGO Growth}

The different samples of TBC with the idealized and actual microstructures (shown in Figure $1 \mathrm{c}, \mathrm{d}$ ) are adopted to investigate TGO growth, as shown in Figure 5.

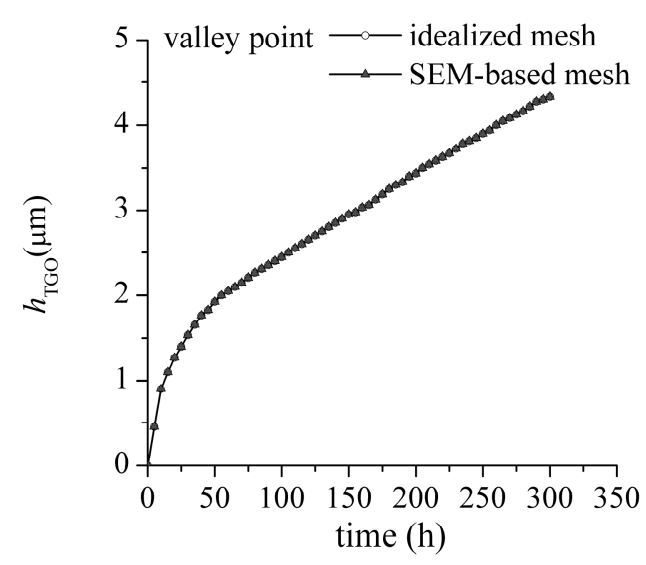

(a)

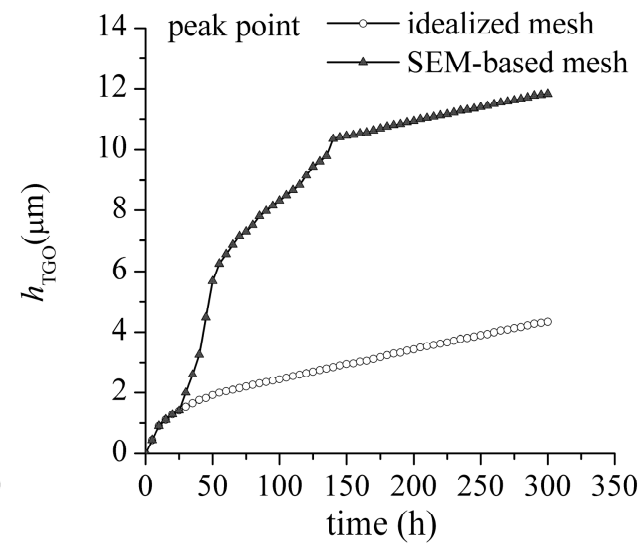

(b)

Figure 5. Evolutions of TGO thickness in (a) the valley and (b) peak regions of both meshes.

As shown in Figure 1c,d, there are nearly identical microstructure features for different samples of TBC in the valley regions. It indicates that there are similar influences of microstructures on TGO growth in the valley regions. Thus, the almost identical evolutions of TGO thickness for different samples of TBC are observed in Figure 5a. In the peak region of different samples of TBC, the evolutions of TGO thickness, however, are significantly different, as shown in Figure 5b. It could be found in Figure $1 c$, there are many interface defects in the peak region of actual microstructures. This increases the surface-area-to-volume ratio of $\mathrm{BC}$ exposed to oxygen anion and promotes TGO growth. These actual microstructures could be accurately represented in the SEM-based mesh, but be omitted in the idealized mesh, which leads to the differences for the evolutions of TGO growth in the peak region of both meshes.

The contour plots of TGO thickness, after 50, 150, and $300 \mathrm{~h}$ oxidation, are illustrated in Figure 6. As shown in Figure 6a-c, the uniform growth of TGO, with oxidation, is observed in the sample TBC with idealized microstructures. While the TGO growth is non-uniform in the sample of TBC with actual microstructures. As shown in Figure 6d, the relative thin portions of $B C$ in the peak region are 
fully oxidized at the initial stage of oxidation. Meanwhile, one part of $\mathrm{BC}$ is completely encapsulated with TGO, which leads to the formation of an isolated $\mathrm{BC}$ cluster in the peak region. The isolated $\mathrm{BC}$ cluster increases the surface-area-to-volume ratio of $\mathrm{BC}$, exposed to oxygen anion, and promotes local TGO growth. Thus, thicker TGO could be observed in the peak region, as shown in Figure 6e,d.

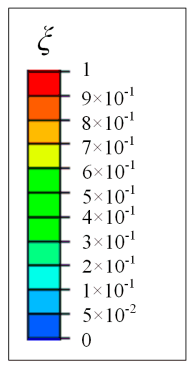

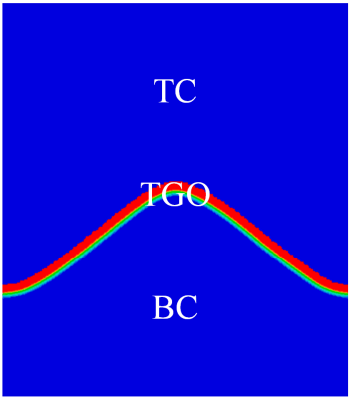

(a)

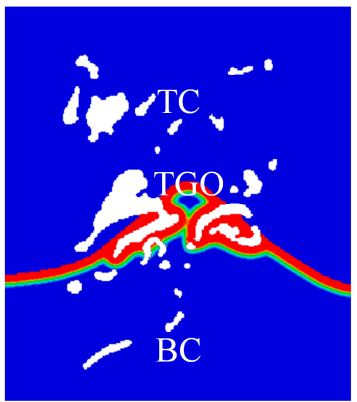

(d)

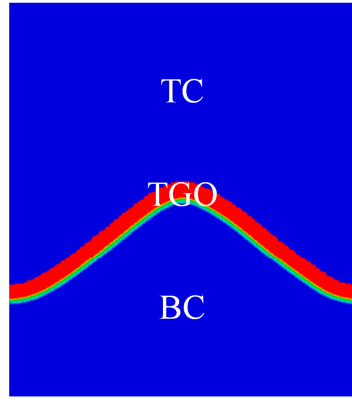

(b)

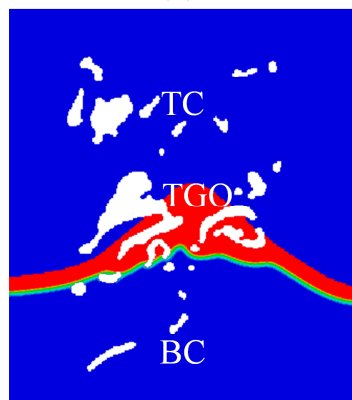

(e)

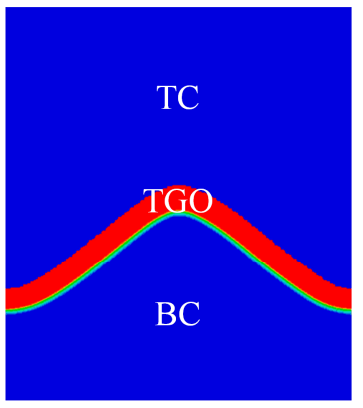

(c)

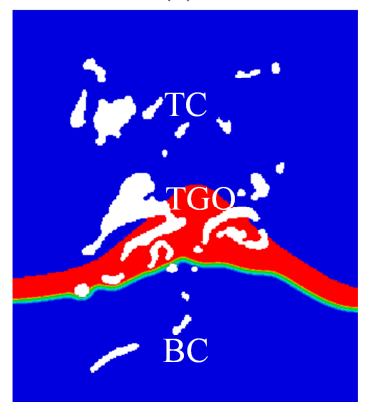

(f)

Figure 6. The contour plots of TGO thickness after (a) 50, (b) 150, and (c) $300 \mathrm{~h}$ oxidation for the idealized TBC, and TGO layer in TBC with actual microstructures after (d) 50, (e) 150, and (f) $300 \mathrm{~h}$ oxidation

The evolutions of molar friction of TGO at the points $\mathrm{P}$ of different samples of TBC are compared in Figure 7. It is obvious that the oxidation rate is faster for the sample of TBC with actual microstructures at the point $P$. This suggests again that the interface defects lead to the non-uniform growth of TGO. While it is has not been reported in the previous literatures, in which the idealized microstructures are adopted in simulations, the non-uniform growth of TGO has been observed in experiments (see Figure $3 b$ in reference [29]).

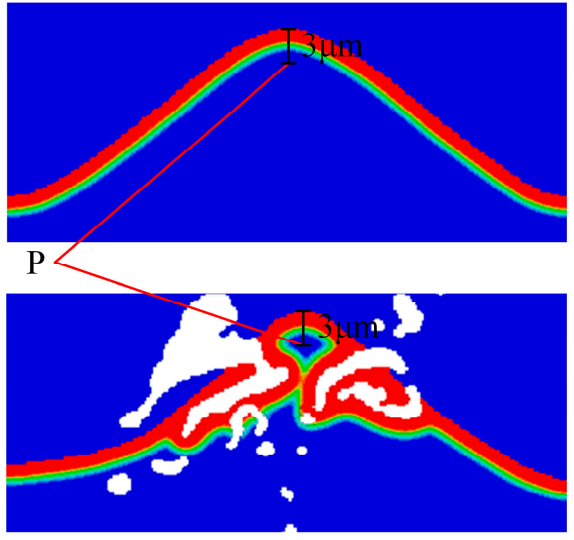

(a)

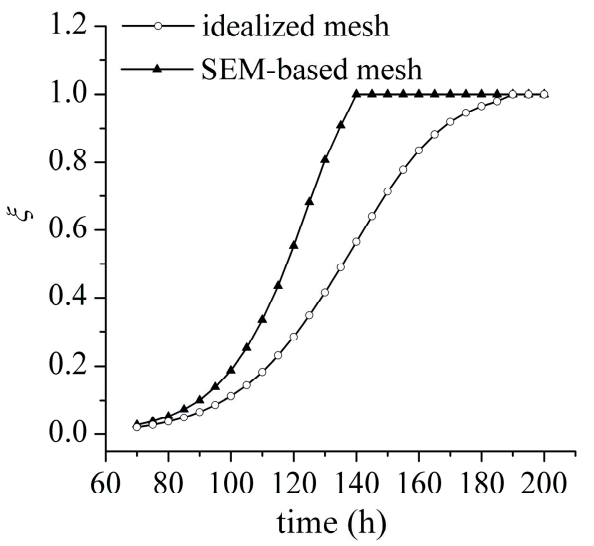

(b)

Figure 7. (a) The contour plot of TGO layer and the location of points P of both TBC samples and (b) the evolutions of molar friction of TGO at the points P. 


\subsection{Stress Evolution}

\subsubsection{Stress Evolution Affected by Microstructure Features}

The interface stress evolution affected by Microstructure features is investigated. In this case, TC is assumed to be elastic material. BC and TGO are regarded as perfect elastic-to-plastic material. The contour plots of stress $\sigma_{22}$, after 300 h oxidation at 1373 and $293 \mathrm{~K}$, are illustrated in Figure 8.

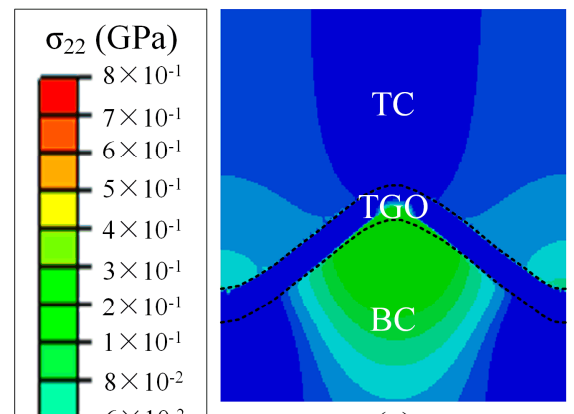

(a)

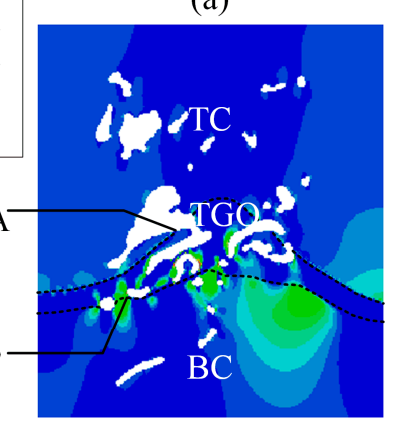

(c)

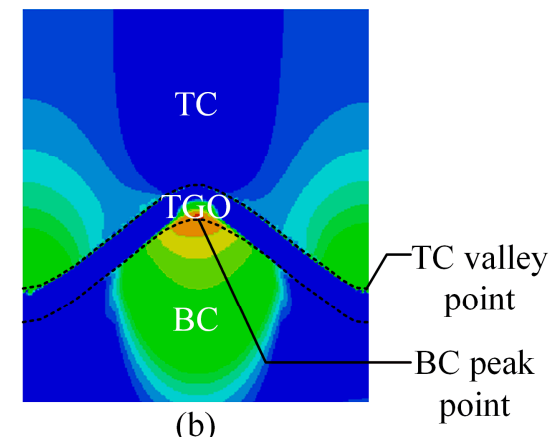

(b)

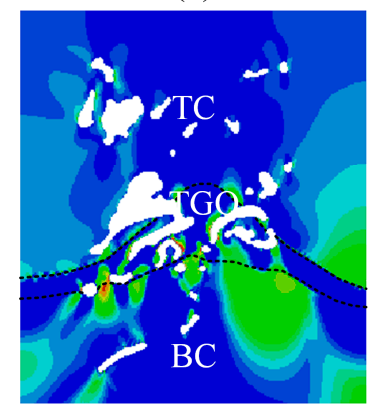

(d)

Figure 8. Contour plots of stress $\sigma_{22}$, after $300 \mathrm{~h}$ oxidation (a) at $1373 \mathrm{~K}$ and (b) $293 \mathrm{~K}$ in the sample of TBC with ideal interface and (c) at $1373 \mathrm{~K}$ and (d) $293 \mathrm{~K}$ in the sample of TBC with actual microstructures.

During oxidation, the interface stress is mainly induced by the out-of-plane deformation of TGO associated with the permanent volumetric swelling. In the sample of TBC with idealized microstructures, such an out-of-plane deformation of TGO leads to the tension in TC valley and BC peak regions, as well as the compression in the TC peak and BC valley regions, as shown in Figure 8a. The corresponding maximum stresses $\sigma_{22}$ along TC-TGO and TGO-BC interfaces are, respectively, at the TC valley and BC peak points. When TBC is cooled down to $293 \mathrm{~K}$, there are no obvious changes in the distribution of stress $\sigma_{22}$, but the magnitudes of stress increases rapidly due to the thermal expansion mismatch at the cooling stage, as shown in Figure $8 \mathrm{~b}$. The distribution of stress $\sigma_{22}$, in the idealized mesh, is similar with the previous numerical studies $[14,16]$, which demonstrates the accuracy of the present simulation. In the sample of TBC with actual microstructures, the stress discontinuities occur due to the irregular interface-morphology and randomly-distributed microdefects (see Figure $8 \mathrm{c}, \mathrm{d}$ ). The corresponding maximum tensile stresses $\sigma_{22}$ in TC and $\mathrm{BC}$ layers are, respectively, at the locations A and B near interface defects, rather than TC valley and BC peak points. The maximum stresses $\sigma_{22}$ along TC-TGO and TGO-BC interfaces with idealized and real microstructures are also plotted in Figure 9. It could be found that when TBC is cooled down to $293 \mathrm{~K}$, the maximum stresses $\sigma_{22}$ in TC and BC with actual microstructures, are, respectively, 0.327 and $0.857 \mathrm{GPa}$. The values are approximately 1.5 times as large as those in the idealized mesh. It might induce growth and consolidation of microdefects and finally lead to delamination of TBC. It means that interface defects could significantly affect the distribution and magnitude of interface stress. Thus, the consideration of actual microstructure features in FE mesh would be helpful for the accurate evaluation of interface stress for TBC. 


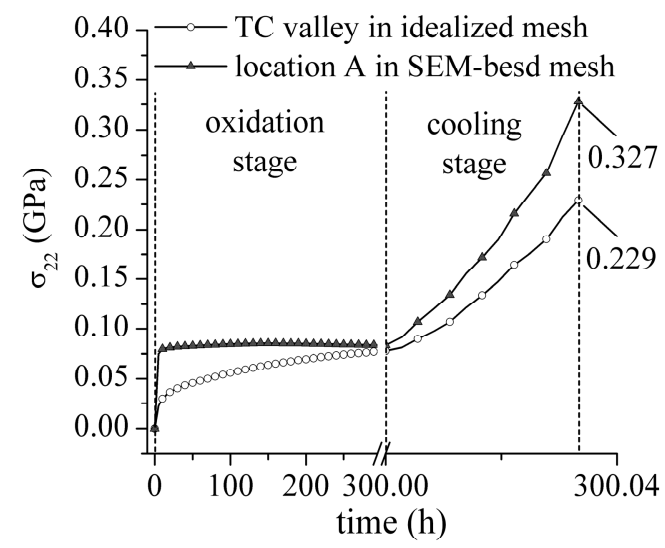

(a)

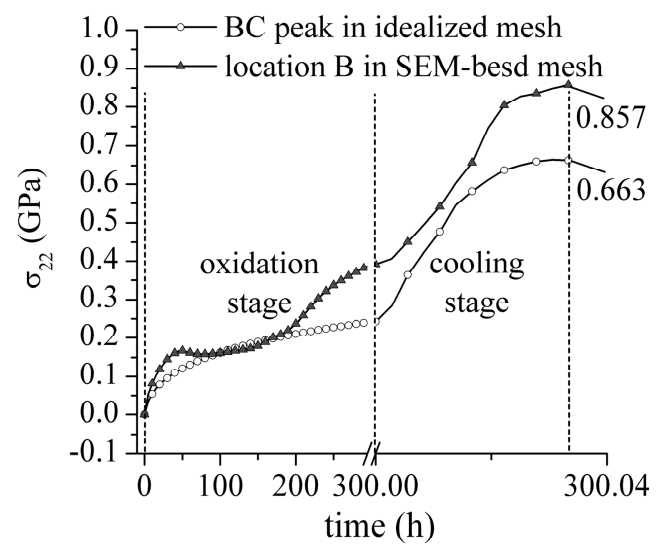

(b)

Figure 9. Evolution of maximun $\sigma_{22}$ in (a) TC layer and (b) BC layer.

\subsubsection{Stress Evolution Affected by Mechanical Behavior}

The interface stress evolution is also significantly affected by the mechanical behavior during serving. Therefore, by considering the SD property and the creep-plastic behavior, the high temperature oxidation simulation for TBC is implemented. Only the sample of TBC with actual microstructures is used to investigate the stress evolution. The contour plots of stress $\sigma_{22}$, after $300 \mathrm{~h}$ oxidation at $1373 \mathrm{~K}$, are illustrated in Figure 10. Here, TC is assumed to be elastic in Figure 10a,b and elastic-to-plastic with SD property in Figure 10c. TGO and BC are assumed to be elastic-to-plastic in Figure 10a and creep-plastic in Figure 10b,c.

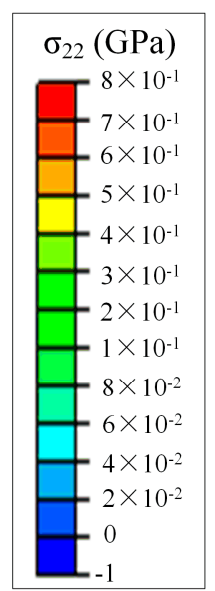

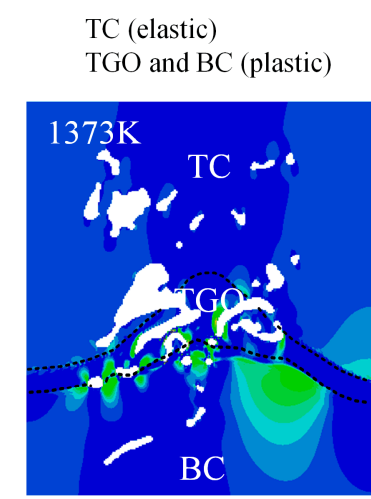

(a)

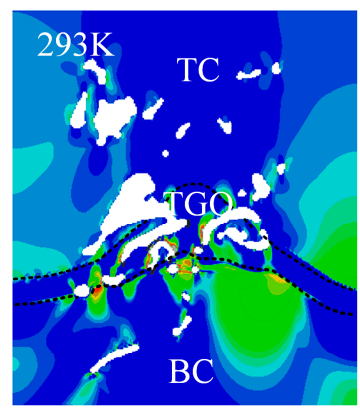

(d)

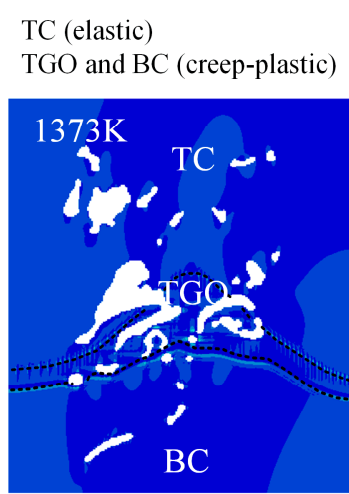

(b)

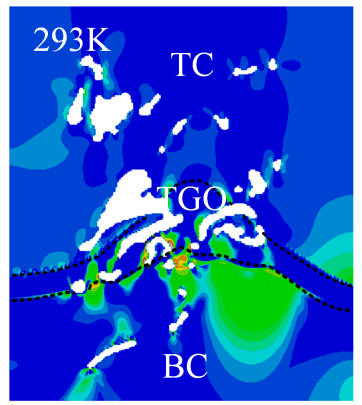

(e)
TC (plastic with SD property) $\mathrm{TGO}$ and $\mathrm{BC}$ (creep-plastic)

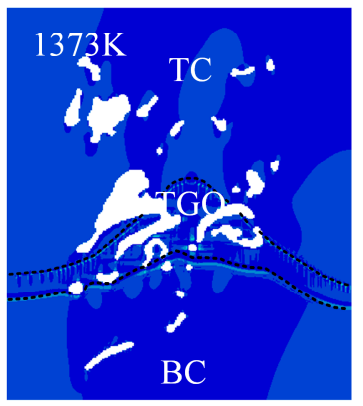

(c)

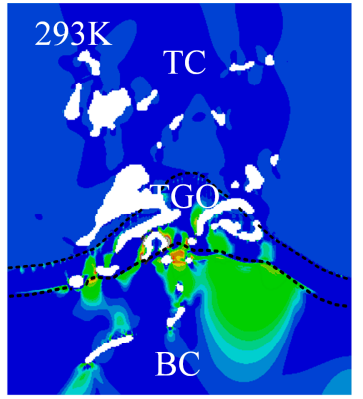

(f)

Figure 10. Contour plots of stress $\sigma_{22}$ in (a-c) TBC with ideal interface and (d-f) TBC with actual microstructures. And the different mechanical assumptions are considered: (a,d) TC is elastic, TGO and BC are elastic to plastic; (b,e) TC is elastic, TGO and BC are creep-plastic; (c,f) TC is plastic with SD property, TGO and BC are creep-plastic. 
It could be observed that when TGO and BC are assumed to be elastic-to-plastic, the considerable stress generates near the interface and defect, as shown in Figure 10a. While the approximate zero-stress state is observed in Figure 10b, if the TGO and BC are considered to be the creep-plastic materials. The compressive growth stress, generating TGO, is relaxed rapidly by the sizable creep deformation. This weakens the out-of-plane displacement of the TGO layer, which is induced by the compressive growth stress. Finally, it suppresses the stress accumulation in TBC. If the SD property of TC is considered, the stress near the TC-TGO interface would be even smaller by comparing it with the stress contour plots in Figure 10b,c. It means that by taking the elastic-to-plastic assumption with the SD property into account, the plastic deformation occurs in the TC layer. It effectively reduces the stress-level.

When TBC is cooled down to room temperature $293 \mathrm{~K}$, the stress contour plots with different material assumptions are also illustrated in Figure 10d-f. By comparing the stress state in Figure 10d,e, it is observed that when TGO and BC is considered to be creep-plastic, the stress state would be smaller. It means that the creep behavior of TGO and BC not only exhibit at the continuous high temperature stage, but also occurs at the cooling stage. The creep deformation relatively relaxes the stress generation, which is induced by the thermal expansion mismatch of different layers during cooling. When TC is considered to be the elastic-to-plastic material with SD property (see Figure 10f), the plastic deformation in TC would lead to a further reduction of stress level near the TC-TGO interface, compared with the stress in Figure 10e.

\section{Conclusions}

In present paper, three new considerations are proposed to investigate TGO growth and stress development in TBC. The SEM image-based direct FE mesh reconstruction method is utilized to represent the actual microstructure features of TBC. SD property of TC and creep-plastic assumption of TGO and BC are considered to simulate mechanical behavior. The diffusion-oxidation model is proposed to characterize TGO growth. The results reveal that:

- The interface defects increase the surface-area-to-volume ratio of BC exposed to oxygen anion. It leads to the non-uniform growth of TGO in the actual microstructures. It has also been observed in experimental studies (see Figure $3 \mathrm{~b}$ in Reference [28]).

- The interface defects significantly affects the magnitude and distribution of interface stress. The consideration of actual microstructure features is helpful for the accurate evaluation of interface stress for TBC.

- The mechanical behavior strongly affects stress evolution in TBC. The sizable creep deformation of TGO and BC can significantly relax the growth stress and leads to the approximate zero-stress state during the continuous high temperature stage. When the SD property of TC is considering, the plastic deformation easily occurs in the TC layer. It leads to the considerable reduction of stress-level in the TC layer.

Author Contributions: Conceptualization, C.L. in and Y.L.; Methodology, C.L. and Y.L.; Software, C.L.; Validation, C.L. and Y.C.; Formal Analysis, C.L.; Investigation, C.L.; Resources, Y.L.; Data Curation, C.L; Writing-Original Draft Preparation, C.L.; Writing-Review \& Editing, Y.L., C.L. and Y.C.; Visualization, C.L.; Supervision, Y.L.; Project Administration, Y.L.; Funding Acquisition, Y.L.

Funding: This research was funded by the National nature science foundation of China (grant number 11472206).

Acknowledgments: This research was supported by the state key laboratory for strength and vibration of mechanical structures, $\mathrm{Xi}^{\prime}$ an Jiaotong University. We are grateful for the support.

Conflicts of Interest: The authors declare no conflict of interest.

\section{Appendix A.}

As illustrated in Figure A1a, there are six different stress-update possibilities in the sextant of principal stress space $\sigma_{1} \geq \sigma_{2} \geq \sigma_{3}$ for UST model: stress-updates at the main plane 1, main plane 2, 
left corner, middle corner and apex. In this paper only the processes of stress-update at main plain 1 , middle corner and apex are introduced for simplicity. The associated plastic flow rule, the linear isotropic hardening and the isotropic elasticity are considered.

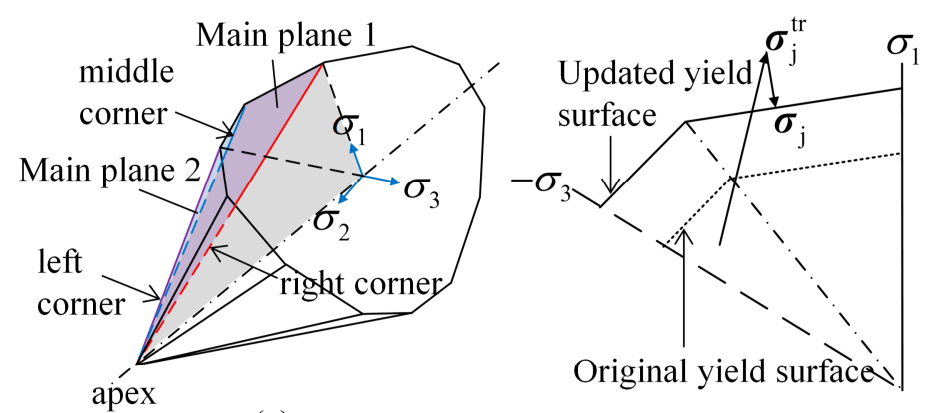

(a)

(b)

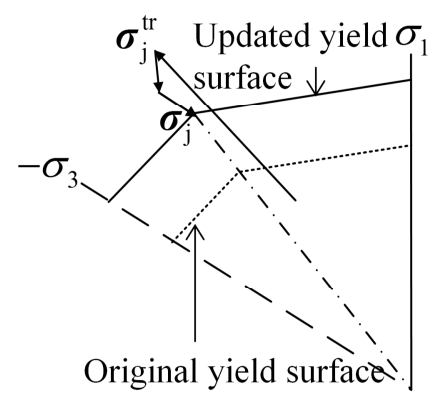

(c)

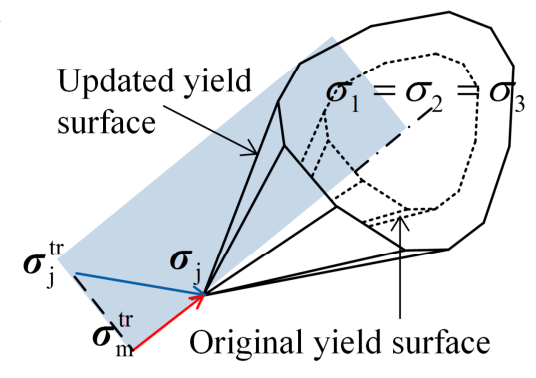

(d)

Figure A1. (a) Six different stress-update possibilities and the stress update schemes at (b) yield plane (c) corner and (d) apex.

Appendix A.1. Stress-Update at Main Plain

As shown in Figure A1b, the constitutive relation can be written as follows,

$$
\sigma_{\mathrm{j}}=\sigma_{\mathrm{j}}^{\mathrm{tr}}-\Delta \lambda D_{3 \times 3}^{\mathrm{e}}: N
$$

where $\sigma_{j}^{\text {tr }}$ and $\sigma_{j}$ are, respectively, the elastic trial principal stress vector and the updated principal stress vector, $\Delta \lambda$ is the plastic flow parameter, $D_{3 \times 3}^{\mathrm{e}}$ is the reduced elastic isotropic constitutive matrix, and $N$ is the reduced plastic flow vector normal to the main plane 1 , expressed as,

$$
N=\left\{\begin{array}{ccc}
1 & \frac{-a b}{1+b} & \frac{-a}{1+b}
\end{array}\right\}^{T}
$$

The updated stresses should lie on the yield surfaces. Substituting the constitutive function Equation (A1) into yield function Equation (1), one obtains,

$$
F: N^{\mathrm{T}}:\left(\sigma_{\mathrm{j}}^{\mathrm{tr}}-\Delta \lambda D_{3 \times 3}^{\mathrm{e}}: N\right)-\left(\sigma_{\mathrm{t}}^{0}+H \Delta \lambda\right)=0
$$

where $\sigma_{t}^{0}$ and $H$ are, respectively, the initial tensile strength and the linear isotropic hardening modulus. From Equation (A3), the plastic flow parameter can be derived to be,

$$
\Delta \lambda=\frac{N^{\mathrm{T}}: \sigma_{j}^{\mathrm{tr}}-\sigma_{\mathrm{t}}^{0}}{N^{\mathrm{T}}: D_{3 \times 3}^{\mathrm{e}}: N+H}
$$

Substituting Equation (A4) into Equation (A1), the updated stresses can be easily obtained. 
Appendix A.2. Stress-Update at Corner

As shown in Figure A1c, the updated stresses lie on the middle corner, the constitutive equation can be written as follow,

$$
\sigma_{\mathrm{j}}=\sigma_{\mathrm{j}}^{\mathrm{tr}}-\Delta \lambda_{1} D_{3 \times 3}^{\mathrm{e}}: N-\Delta \lambda_{2} D_{3 \times 3}^{\mathrm{e}}: N^{\prime}
$$

where $N^{\prime}$ is the plastic flow vector perpendicular to the main plane 2, expressed as,

$$
N=\left\{\begin{array}{ccc}
\frac{1}{1+b} & \frac{b}{1+b} & a
\end{array}\right\}^{T}
$$

If the updated stresses lie on the middle corner, the consistency condition should be satisfied as follows,

$$
\begin{gathered}
F: N^{\mathrm{T}}:\left(\sigma_{\mathrm{j}}^{\mathrm{tr}}-\Delta \lambda_{1} D_{3 \times 3}^{\mathrm{e}}: N-\Delta \lambda_{2} D_{3 \times 3}^{\mathrm{e}}: N \prime\right)-\left[\sigma_{\mathrm{t}}^{0}+H\left(\Delta \lambda^{1}+\Delta \lambda^{2}\right)\right]=0 \\
F \prime: N^{\mathrm{T}}:\left(\sigma_{\mathrm{j}}^{\mathrm{tr}}-\Delta \lambda_{1} D_{3 \times 3}^{\mathrm{e}}: N-\Delta \lambda_{2} D_{3 \times 3}^{\mathrm{e}}: N \prime\right)-\left[\sigma_{\mathrm{t}}^{0}+H\left(\Delta \lambda^{1}+\Delta \lambda^{2}\right)\right]=0
\end{gathered}
$$

By solving the Equations (A7) and (A8), the plastic flow parameters $\Delta \lambda$ and $\Delta \lambda^{\prime}$ can be obtained,

$$
\left\{\begin{array}{c}
\Delta \lambda_{2} \\
\Delta \lambda_{2}
\end{array}\right\}=\left[\begin{array}{cc}
N^{\mathrm{T}}: D_{3 \times 3}^{\mathrm{e}}: N+H & N^{\mathrm{T}}: D_{3 \times 3}^{\mathrm{e}}: N \prime+H \\
N^{\mathrm{T}}: D_{3 \times 3}^{\mathrm{e}}: N+H & N^{\prime}: D_{3 \times 3}^{\mathrm{e}}: N \prime+H
\end{array}\right]^{-1}:\left\{\begin{array}{c}
N^{\mathrm{T}}: \sigma_{\mathrm{j}}^{\mathrm{tr}} \\
N^{\prime}: \sigma_{\mathrm{j}}^{\mathrm{tr}}
\end{array}\right\}
$$

Substituting plastic flow parameters $\Delta \lambda$ and $\Delta \lambda^{\prime}$ into Equations (A7) and (A8), respectively, the explicit expression of updated stresses can be derived easily.

Appendix A.3. Stress-Update at Apex

As shown in Figure A1d, the apex of UST model is along the hydrostatic axis $\left(\sigma_{1}=\sigma_{2}=\sigma_{3}\right)$, substituting $\sigma_{1}=\sigma_{2}=\sigma_{3}$ into Equation (1) or Equation (2), the yield function can be rewritten as,

$$
(1-a) \sigma_{\mathrm{m}}=\sigma_{\mathrm{t}}, \text { when } \sigma_{1}=\sigma_{2}=\sigma_{3}
$$

where $\sigma_{\mathrm{m}}=\left(\sigma_{1}+\sigma_{2}+\sigma_{3}\right) / 3$. At the apex, the general constitutive equation for return mapping is given as follows,

$$
\sigma_{\mathrm{m}}=\sigma_{\mathrm{m}}^{\mathrm{tr}}-K \Delta \varepsilon_{\mathrm{V}}^{\mathrm{p}}
$$

where $\Delta \varepsilon_{\mathrm{v}}^{\mathrm{p}}$ is the volumetric plastic strain increment, written as,

$$
\Delta \varepsilon_{\mathrm{V}}^{\mathrm{p}}=(1-a) \Delta \varepsilon_{\mathrm{eq}}^{\mathrm{p}}
$$

where $\Delta \varepsilon_{\mathrm{eq}}^{\mathrm{p}}$ is the equivalent plastic strain increment. Substituting Equations (A11) and (A12) into Equation (A10), one obtains,

$$
(1-a) \sigma_{\mathrm{m}}^{\mathrm{tr}}-\sigma_{\mathrm{t}}^{0}-\left[K(1-a)^{2}+H\right] \Delta \varepsilon_{\mathrm{eq}}^{\mathrm{p}}=0
$$

Integrating the Equations (A11)-(A13), the explicit formulation of updated stresses are derived as follows,

$$
\sigma_{1}=\sigma_{2}=\sigma_{3}=\frac{H}{K(1-a)^{2}+H} \sigma_{\mathrm{m}}^{\mathrm{tr}}+\frac{K(1-a) \sigma_{\mathrm{t}}^{0}}{K(1-a)^{2}+H}
$$




\section{Appendix B.}

To numerically solute the creep-plastic constitutive model, the return-mapping algorithm proposed by [30] is adopted. For simplicity, only the constitutive model of TGO is adopted here. Assuming one time increment $\Delta t_{n+1}=t_{n+1}-t_{n}$, the creep-plastic constitutive model is in the form,

$$
\sigma_{\mathrm{TGO}}=\left.\sigma_{\mathrm{TGO}}^{\mathrm{tr}}\right|_{\mathrm{n}+1}-D_{\mathrm{TGO}}^{\mathrm{e}}:\left(\left.\Delta \varepsilon_{\mathrm{TGO}}^{\mathrm{p}}\right|_{\mathrm{n}+1}+\left.\Delta \varepsilon_{\mathrm{TGO}}^{\mathrm{c}}\right|_{\mathrm{n}+1}\right)
$$

where $\sigma_{\mathrm{TGO}}^{\mathrm{tr}}$ is the elastic trail stresses of TGO, expressed as,

$$
\left.\sigma_{\mathrm{TGO}}^{\mathrm{tr}}\right|_{\mathrm{n}+1}=D_{\mathrm{TGO}}^{\mathrm{e}}:\left(\left.\varepsilon_{\mathrm{TGO}}\right|_{\mathrm{n}+1}-\left.\varepsilon_{\mathrm{TGO}}^{\mathrm{th}}\right|_{\mathrm{n}+1}-\left.\varepsilon_{\mathrm{TGO}}^{\mathrm{g}}\right|_{\mathrm{n}+1}-\left.\varepsilon_{\mathrm{TGO}}^{\mathrm{p}}\right|_{\mathrm{n}}-\left.\varepsilon_{\mathrm{TGO}}^{\mathrm{c}}\right|_{\mathrm{n}}\right)
$$

If the trail stress lies within the yield limit, i.e.,

$$
\left.q\left(\sigma_{\mathrm{TGO}}^{\mathrm{tr}}\right)\right|_{\mathrm{n}+1}-\sigma_{\mathrm{y}, \mathrm{TGO}} \leq 0
$$

where $q$ is the von-Mises equivalent stress; $\sigma_{\mathrm{y}}$, TGO is the yield strength of TGO, the trail stress, must be relaxed by creep. The expression of final stress, in Equation (A15), is reduced in the form,

$$
\sigma_{\mathrm{TGO}}=\left.\sigma_{\mathrm{TGO}}^{\mathrm{tr}}\right|_{\mathrm{n}+1}-D_{\mathrm{TGO}}^{\mathrm{e}}:\left.\Delta \varepsilon_{\mathrm{TGO}}^{\mathrm{c}}\right|_{\mathrm{n}+1}
$$

where the creep strain increment is in the form,

$$
\left.\Delta \varepsilon_{\mathrm{TGO}}^{\mathrm{c}}\right|_{\mathrm{n}+1}=\left.\left.\Delta t_{\mathrm{n}+1} \frac{d \varepsilon_{\mathrm{eq}, \mathrm{TGO}}^{\mathrm{c}}}{d t}\right|_{\mathrm{n}+1} \frac{\partial q\left(\sigma_{\mathrm{TGO}}\right)}{\partial \sigma_{\mathrm{TGO}}}\right|_{\mathrm{n}+1}
$$

In Equation (A19), $d \varepsilon_{\text {eq,TGO }}^{\mathrm{c}} / d t$ is the equivalent creep strain rate, expressed as,

$$
\left.\frac{d \varepsilon_{\mathrm{eq}, \mathrm{TGO}}^{\mathrm{c}}}{d t}\right|_{\mathrm{n}+1}=A_{\mathrm{TGO}} \exp \left(-\frac{Q_{\mathrm{TGO}}}{R T}\right)\left(\left.q\left(\sigma_{\mathrm{TGO}}\right)\right|_{\mathrm{n}+1}\right)^{\rho_{\mathrm{TGO}}}
$$

When the trail stress, lies outside the yield surface, i.e.,

$$
\left.q\left(\sigma_{\mathrm{TGO}}^{\mathrm{tr}}\right)\right|_{\mathrm{n}+1}-\sigma_{\mathrm{y}, \mathrm{TGO}}>0
$$

the creep-type return-mapping scheme, as expressed in Equation (A18), is employed to update stress state firstly. If the updated stress lies within the yield limit, the creep-type return-mapping scheme is valid. Otherwise, the creep-plastic return-mapping scheme, as expressed in Equation (A15), is implemented. The final stress must lie on the yield surface, so the equivalent creep strain rate become the constants in the form,

$$
\left.\frac{d \varepsilon_{\mathrm{eq}, \mathrm{TGO}}^{\mathrm{c}}}{d t}\right|_{\mathrm{n}+1}=A_{\mathrm{TGO}} \exp \left(-\frac{Q_{\mathrm{TGO}}}{R T}\right)\left(\left.\sigma_{\mathrm{y}, \mathrm{TGO}}\right|_{\mathrm{n}+1}\right)^{\rho_{\mathrm{TGO}}}
$$

The corresponding plastic strain increment is expressed as,

$$
\left.\Delta \varepsilon_{\mathrm{TGO}}^{\mathrm{p}}\right|_{\mathrm{n}+1}=\left.\left.\Delta \varepsilon_{\mathrm{eq}, \mathrm{TGO}}^{\mathrm{p}}\right|_{\mathrm{n}+1} \frac{\partial q\left(\sigma_{\mathrm{TGO}}\right)}{\partial \sigma_{\mathrm{TGO}}}\right|_{\mathrm{n}+1}
$$




\section{References}

1. Padture, N.P. Advanced structural ceramics in aerospace propulsion. Nat. Mater. 2016, 15, 804-809. [CrossRef] [PubMed]

2. Kumar, V.; Balasubramanian, K. Progress update on failure mechanisms of advanced thermal barrier coatings: A review. Prog. Org. Coat. 2016, 90, 54-82. [CrossRef]

3. Maurel, V.; Busso, E.P.; Frachon, J.; Besson, J.; N'Guyen, F. A methodology to model the complex morphology of rough interfaces. Int. J. Solids Struct. 2014, 51, 3293-3302. [CrossRef]

4. Moridi, A.; Azadi, M.; Farrahi, G.H. Thermo-mechanical stress analysis of thermal barrier coating system considering thickness and roughness effects. Surf. Coat. Technol. 2014, 243, 91-99. [CrossRef]

5. Ahmadian, S.; Browning, A.; Jordan, E.H. Three-dimensional X-ray micro-computed tomography of cracks in a furnace cycled air plasma sprayed thermal barrier coating. Scr. Mater. 2015, 97, 13-16. [CrossRef]

6. Nayebpashaee, N.; Seyedein, S.H.; Aboutalebi, M.R.; Sarpoolaky, H.; Hadavi, S.M.M. Finite element simulation of residual stress and failure mechanism in plasma sprayed thermal barrier coatings using actual microstructure as the representative volume. Surf. Coat. Technol. 2016, 291, 103-114. [CrossRef]

7. Wei, S.; Qun-Bo, F.; Fu-Chi, W.; Zhuang, M. Modeling of micro-crack growth during thermal shock based on microstructural images of thermal barrier coatings. Comput. Mater. Sci. 2009, 46, 600-602. [CrossRef]

8. Huang, M.; Li, Y.-M. X-ray tomography image-based reconstruction of microstructural finite element mesh models for heterogeneous materials. Comput. Mater. Sci. 2013, 67, 63-72. [CrossRef]

9. Demasi-Marcin, J.T.; Sheffler, K.D.; Bose, S. Mechanisms of degradation and failure in a plasma-deposited thermal barrier coating. J. Eng. Gas. Turb. Power 1990, 112, 521-526. [CrossRef]

10. Rejda, E.F.; Socie, D.F.; Itoh, T. Deformation behaviour of plasma-sprayed thick thermal barrier coatings. Surf. Coat. Technol. 1999, 113, 218-226. [CrossRef]

11. Yu, M.-H. Unified strength theory (UST). In Unified Strength Theory and Its Applications; Springer: Singapore, 2018; pp. 151-190.

12. Lin, C.; Li, Y.M. A return mapping algorithm for unified strength theory model. Int. J. Numer. Methods Eng. 2015, 104, 749-766. [CrossRef]

13. Lin, C.; Sun, Q.; Chai, Y.; Chen, H.L.; Li, Y.M. Stress evolution in top coat of thermal barrier coatings by considering strength difference property in tension and compression. Surf. Coat. Technol. 2017, 329, 86-96. [CrossRef]

14. He, M.Y.; Hutchinson, J.W.; Evans, A.G. Simulation of stresses and delamination in a plasma-sprayed thermal barrier system upon thermal cycling. Mater. Sci. Eng. A 2003, 345, 172-178. [CrossRef]

15. Busso, E.P.; Qian, Z.Q.; Taylor, M.P.; Evans, H.E. The influence of bondcoat and topcoat mechanical properties on stress development in thermal barrier coating systems. Acta Mater. 2009, 57, 2349-2361. [CrossRef]

16. Seiler, P.; Bäker, M.; Rösler, J. Multi-scale failure mechanisms of thermal barrier coating systems. Comput. Mater. Sci. 2013, 80, 27-34. [CrossRef]

17. Bäker, M. Influence of material models on the stress state in thermal barrier coating simulations. Surf. Coat. Technol. 2014, 240, 301-310. [CrossRef]

18. Caliez, M.; Feyel, F.; Kruch, S.; Chaboche, J.L. Oxidation induced stress fields in an EB-PVD thermal barrier coating. Surf. Coat. Technol. 2002, 157, 103-110. [CrossRef]

19. Frost, H.J.; Ashby, M.F. Deformation Mechanism Maps: The Plasticity and Creep of Metals and Ceramics; Pergamon Press: Oxford, UK, 1982.

20. Lin, C.; Li, Y.M. Interface stress evolution considering the combined creep-plastic behaviour in thermal barrier coatings. Mater. Des. 2016, 89, 245-254. [CrossRef]

21. Busso, E.P.; Lin, J.; Sakurai, S.; Nakayama, M. A mechanistic study of oxidation-induced degradation in a plasma-sprayed thermal barrier coating system. Part I: Model formulation. Acta Mater. 2001, 49, 1515-1528. [CrossRef]

22. Zhao, L.G.; O'Dowd, N.P.; Busso, E.P. A coupled kineticconstitutive approach to the study of high temperature crack initiation in single crystal nickel-base superalloys. J. Mech. Phys. Solids 2006, 54, 288-309. [CrossRef]

23. Ulm, F.J.; Coussy, O.; Kefei, L.; Larive, C. Thermo-chemo-mechanics of ASR expansion in concrete structures. J. Eng. Mech. 2000, 126, 233-242. [CrossRef] 
24. Chu, H.N. High-frequency extensional vibrations of sandwich plates. J. Acoust. Soc. Am. 1962, 34, 1184-1190. [CrossRef]

25. Loeffel, K.; Anand, L.; Gasem, Z.M. On modeling the oxidation of high-temperature alloys. Acta Mater. 2013, 61, 399-424. [CrossRef]

26. Cheng, J.; Jordan, E.H.; Barber, B.; Gell, M. Thermal/residual stress in an electron beam physical vapor deposited thermal barrier coating system. Acta Mater. 1998, 46, 5839-5850. [CrossRef]

27. Wereszczak, A.A.; Hemrick, J.G.; Kirkland, T.P.; Haynes, J.A.; Fitzgerald, T.J.; Junkin, J.E. Stress relaxation of MCrAlY bond coat alloys as a function of temperature and strain. In Proceeding of the ASME 1998 International Gas Turbine and Aeroengine Congress and Exhibition, Stockholm, Sweden, 2-5 June 1998; ASME: West Conshohocken, PA, USA, 1998.

28. Quested, P.N.; Brooks, R.F.; Chapman, L.; Morrell, R.; Youssef, Y.; Mills, K.C. Measurement and estimation of thermophysical properties of nickel based superalloys. Mater. Sci. Technol. 2009, 25, 154-162. [CrossRef]

29. Padture, N.P.; Gell, M.; Jordan, E.H. Thermal barrier coatings for gas-turbine engine applications. Science 2002, 296, 280-284. [CrossRef] [PubMed]

30. De Souza Neto, E.A.; Peric, D.; Owen, D.R. Computational Methods for Plasticity: Theory and Applications; John rtWiley \& Sons: Chichester, UK, 2008; ISBN 9780470694626.

(C) 2018 by the authors. Licensee MDPI, Basel, Switzerland. This article is an open access article distributed under the terms and conditions of the Creative Commons Attribution (CC BY) license (http://creativecommons.org/licenses/by/4.0/). 